Revista de Estudios Histórico-Jurídicos

[Sección materiales]

XXXIX (Valparaíso, Chile, 2017)

[pp. 379 - 383]

\title{
Cargas PÚblicas y ENRIQUeCIMIENTO SIN CAUSA. UN CASO DEL SIGLO XIX
}

[Public burdens and unjustified enrichment in a 19th century case]

\author{
Rodrigo Céspedes Proto* \\ Manchester University, Reino Unido
}

\section{RESUMEN}

Se publica una sentencia dictada por la Corte de Apelaciones de Santiago, el 23 de septiembre de 1871 que se pronuncia sobre el caso de un abogado que es llamado a servir como juez subrogante y se niega a proveer a menos que se le pague por la parte demandante la justa compensación.

\section{Palabras clave}

Cargas públicas - Enriquecimiento sin causa.

\section{Abstract}

Publication of a resolution handed down by the Court of Appeal of Santiago on September $23^{\text {rd }}, 1871$, referring to the case of a lawyer that was summoned to perform as deputy judge and who refused to do so unless the claimants paid the pertinent compensation.

KEYWORDS

Public burdens - Unjustified enrichment.

ReCibIDO el 2 de abril y ACEPTADO el 23 de junio de 2017

* Research Associate, Law School, Manchester University, rodrigo.cespedes@manchester. ac.uk. Investigación financiada por el European Research Council (Advanced Grant: 323656STC). 


\section{INTRODUCCIÓN}

Comentamos un caso simple resuelto equitativamente de manera clara y sin mayores pretensiones. La sentencia tiene varios aspectos interesantes: supremacía constitucional y la interpretación sistemática del ordenamiento, las cargas públicas y el enriquecimiento sin causa. Un abogado es llamado a servir como juez subrogante y se niega a proveer a menos que se le pague por la parte demandante la justa compensación. En opinión del peticionario, el cargo debe servirse gratuitamente. La Corte rechaza esta tesis usando como base el artículo 149 de la Carta de 1833 , la cúspide de la pirámide normativa ${ }^{1}$ y de allí argumenta su decisión. El reglamento de justicia debe integrarse e interpretarse conforme a la Constitución y demás normas del ordenamiento, y no se puede entonces "inferir que esta lei haya $\mathrm{t}$ a $\mathrm{m}$ b i é n querido imponerles el gravamen de servir gratuitamente"; por lo tanto, el subrogante "tiene derecho para exijir a las partes el honorario correspondiente”, que según la legislación vigente era de cargo de las partes.

La Constitución es la cúspide del ordenamiento y toda norma inferior abiertamente en contradicción con la norma superior es nula y de ningún valor. Si no es el caso, el juez debe buscar la forma de integrar e interpretar conciliatoriamente ambas clases de normas. El caso en comento considera estas ideas. Para salvaguardar el principio de supremacía constitucional el ordenamiento debe considerarse como un todo, integrar e interpretar las normas de manera que la solución jurisdiccional tenga sentido. La Constitución es la norma suprema para el Estado (ejecutivo, legislativo y judicial), entes descentralizados, los grupos intermedios y las personas naturales. La creación de normas de inferior jerarquía (legislación y actos administrativos) se sujeta a ésta en cuanto al procedimiento y el contenido. Los actos jurisdiccionales deben reconocer a esta supremacía, en este caso integrando e interpretando la norma inferior (artículos 37 y 72 del reglamento de administración de justicia de 1824) con la disposiciones constitucionales (artículos 12 No $4^{2}, 12$ No $6^{3}, 37$ No $1^{4}, 148^{5}$ y 149 ) y las demás normas dictadas conforme

"No puede exijirse ninguna especie de servicio personal o de contribución, sino en virtud de un decreto de autoridad competente, deducido de la lei que autoriza aquella exacción, i manifestándose el decreto al contribuyente en el acto de imponerle el gravamen".

2 "La igual repartición de los impuestos i contribuciones a proporción de los haberes, i la igual repartición de las demás cargas públicas. Una lei particular determinará el método de reclutas $i$ reemplazos para las fuerzas de mar i tierra".

3 "La inviolabilidad de todas las propiedades, sin distinción de las que pertenezcan a particulares o comunidades, i sin que nadie pueda ser privado de la de su dominio, ni de una parte de ella por pequeña que sea, o del derecho que a ella tuviere, sino en virtud de sentencia judicial; salvo el caso en que la utilidad del Estado, calificada por una lei, exija el uso o enajenación de alguna; lo que tendrá lugar dándose previamente al dueño la indemnización que se ajustare con él, o se avaluare a juicio de hombres buenos".

4 "Sólo en virtud de una lei se puede: $1^{\circ}$ Imponer contribuciones de cualquiera clase o naturaleza, suprimir las existentes $i$ determinar en caso necesario su repartimiento entre las provincias o departamentos".

5 "Sólo el Congreso puede imponer contribuciones directas o indirectas, i sin su especial autorización es prohibido a toda autoridad del Estado i a todo individuo imponerlas, aunque sea bajo pretesto precario voluntario, o de cualquiera otra clase". 
a ella (lei de 26 de noviembre de 1845 y supremo decreto de 7 de noviembre de 1827). El poder público no debe imponer una regla jurídica si ésta no se conforma con ciertos principios prioritarios y jerárquicamente superiores, como la igual repartición de las cargas públicas y el enriquecimiento sin causa.

Para Locke la propiedad es un derecho natural e inalienable, y es deber del Estado garantizar estos derechos. Él considera la propiedad como una emanación del trabajo. Locke estimaba que la protección del derecho de propiedad, la separación de poderes públicos y el control entre ellos eran la base del resguardo de los derechos de las personas y la contención de los potenciales abusos del Estado, incluyendo al poder legislativo, el más importante por representar al pueblo. El mismo Locke sostenía que el poder estatal estaba limitado por derechos fundamentales y su violación autorizaba la desobediencia frente a una pretensión injusta ${ }^{6}$. Es lo que hace el juez subrogante al negarse "a proveer las solicitudes que se le presentan porque no se le paga honorario", una forma de autotutela que la Corte no declara ilegítima. Por lo tanto, no lo puede compeler "a proseguir en el conocimiento de la causa" ya que la ley no le "obliga a servir sin recompensa". Estos principios influyeron en la Revolución Francesa y americana y de allí pasaron a sus textos constitucionales. La Constitución de 1833 sigue este orden de ideas. Lo interesante es que los tribunales de la época consistentemente protegían esos derechos frente a muchos tipos de infracción ${ }^{7}$.

Las cargas públicas son formas de contribución forzosa de los particulares para el cumplimiento de los fines y supervivencia de la comunidad, el sacrificio de cada uno por el bien de todos. Éstas implican un detrimento del patrimonio, del tiempo o la libertad individual. Pueden implicar tributos, servicio militar, deberes electorales, la posibilidad de ser jurado o el deber de comparecer como testigo en juicio. Las cargas públicas se imponen por ley y deben tener carácter general para ser soportadas sin compensación. En este caso se grava especialmente a un individuo que desempeña temporalmente la función jurisdiccional y, consecuencialmente, el trabajo y tiempo empleado debe ser adecuadamente compensado siguiendo la Constitución y el resto del ordenamiento. El artículo 37 del reglamento de justicia impone una carga pública especial y no puede interpretarse de modo que, por la labor desempeñada, "no hai obligacion de satisfacerle" ninguna remuneración. Si el Tribunal declara "que no tiene derecho para exijir remuneracion por sus servicios" infringiría la ley suprema y malinterpretaría el ordenamiento. Al mismo tiempo, contravendría el enriquecimiento sin causa, uno

${ }^{6}$ Ver Tully, James, A Discourse on Property: John Locke and His Adversaries (Cambridge, CUP, 1982). También, Kramer, Matthew H., John Locke the Origins of Private Property: Philosophical Explorations of Individualism, Community and Equality (Cambridge, CUP, 1997).

${ }^{7}$ Ver Bocksang Hola, Gabriel, El nacimiento del derecho administrativo patrio de Chile (1810-1860) (Santiago, CUP, 2015); ÉL MISMO, Politica jurisdiccional en dispositivos anómalos de sentencias referidas a la administración del Estado (1819-1858), en Revista de Estudios HistóricoJurídicos, 37 (2015), pp. 277-294; ÉL MISMO, La responsabilidad del Estado por secuestros de bienes en la república chilena temprana, en Revista Chilena de Derecho, 41/3 (2014), pp. 1049-1077. También los trabajos y comentarios sobre sentencias del Siglo XIX de Soto KLoss, Eduardo, en especial, 1891. Chile bajo dos gobiernos y dos administraciones, en Ius Publicum 26 (2011), pp. 79-99; 27 (2011), pp. 72-84. 
de los principios que refleja la justicia más elemental. La proscripción y corrección del enriquecimiento injusto está tan íntimamente arraigada en nuestro sistema jurídico que es imposible imaginar un orden jurídico civilizado que base sus instituciones en una idea diferente. Una solución contraria implicaría un evidente atentado contra la equidad más mínima. Nuestros tribunales han caracterizado al enriquecimiento sin causa como "principio de justicia universal"8 y la Corte de Apelaciones honra este concepto.

\section{TEXTO DE LA SENTENCIA}

Don Joaquín Carrasco sobre que se obligue al abogado don Juan Agustín

Guerrero a servir

sin honorario como juez por ministerio de la ley en la causa que se expresa?.

Corte de Apelaciones de Santiago

Sentencia 933. De 15 de marzo de 1871

Gaceta de Tribunales, Año XXX, Septiembre 23 de 1871, Núm. 1.524.

Santiago, marzo 15 de 1871.

Vistos:

El procurador don José Rosendo Rojas por don Joaquín Carrasco se ha presentado exponiendo: que su mandante sigue juicio ejecutivo en San Fernando ante el abogado don Agustín Guerrero como subrogante del juez letrado por ministerio de la ley, y que dicho abogado se niega a proveer las solicitudes que se le presentan porque no se le paga honorario, a pesar de que no hay obligación de satisfacerle ninguno; y pide que el tribunal lo compela a proseguir en el conocimiento de la causa, declarando al mismo tiempo que no tiene derecho para exigir remuneración por sus servicios.

Don Juan Agustín Guerrero en el informe que sobre esa reclamación ha evacuado, dice: que el art. 37 del reglamento de administración de justicia no hace más que llamar a los abogados para que subroguen al juez de letras; pero que esta ley ni otra alguna les obliga a servir sin recompensa a los que no están declarados pobres, y que él cobra lo que el arancel vigente manda pagar a los relatores por lectura de autos, que es lo mismo que se paga siempre a los abogados por todo dictamen o resolución que expiden.

Considerando: Que, según lo dispuesto en el art. 149 de la Constitución Política del Estado no puede exigirse ninguna especie de servicio personal o de contribución, sino en virtud de un decreto de autoridad competente deducido de la ley que autoriza aquella exacción.

Que el simple llamamiento que hace el art. 37 del reglamento de administración de justicia a los abogados por el orden de su antigüedad para subrogar al juez letrado en los casos de implicancia, recusación u otra imposibilidad para el

\footnotetext{
${ }^{8}$ Corte Suprema, Lauritzen y otros con Fisco, en RDJ. 52 (1955), 9-10, sec. I, pp. 444 ss.

9 Se ha actualizado la ortografía.
} 
despacho, no autoriza para inferir que esta ley haya también querido imponerles el gravamen de servir gratuitamente.

Que el art. 76 de esa misma ley y la de 26 de noviembre de 1845 llaman a los abogados para suplir en los tribunales superiores en caso de implicancia, recusación y otros que ambas leyes designan; y no obstante en todas ellas las partes litigantes se hallan obligadas a pagarles su respectivo honorario, según lo dispuesto en el art. 12 de los adicionales al citado reglamento, y en los arts. 69 y 79 del supremo decreto de 7 de noviembre de 1827, dictado fuerza de ley.

Se declara que el abogado don Juan Agustín Guerrero como subrogante del juez de letras de San Fernando en la causa de que se ha hecho mérito, tiene derecho para exigir a las partes el honorario correspondiente. Hágase saber al reclamando y comuníquese por secretaría al referido abogado. Santa María. Bernales. Vargas Fontecilla. Ugarte Zenteno. Amunátegui. Proveido por la Iltma. Corte de Apelaciones. Frías. 